Mental Health Act (Koffmann et al, 1997). Non-registration with a GP has been shown to be predictive of compulsory admission (Cole et al, 1995) and this is likely to be the greatest mediator of dissatisfaction with psychiatric services in which Black patients are over-represented, particularly those born in the UK (Parkman et al, 1997). It may therefore be necessary to distinguish between the experience and perception of services in patients at different stages of their illness course, as this might indicate at which point difficulties arise in terms of their interaction with health services. It is also necessary to examine intra-ethnic differences in perception of the services, as it appears that rejection of the services is greater among second-generation Black people.

Work currently being done by my colleagues and I at the Maudsley Hospital examining perceptions of racism in Black patients found that $55 \%$ of Black patients reported perceptions of racial bias and discrimination within the health care service. The same study found that second-generation Black patients are more likely than any other group questioned to express a preference for case managers of the same race. It is therefore relevant to assess the demographics of the service providers, particularly with regard to age, cultural allegiance and ethnicity, as this may identify some of the problems that result in dissatisfaction with services among Black patients at both primary and secondary levels. The perception of GPs of feeling less involved in the care of their Black patients also deserves investigation as it may provide further insight into the reluctance of Black patients to become registered with them from the outset.

Bindman, J., Johnson, S., Wright, S., et al (1997) Integration between primary and secondary services in the care of the severely mentally ill: patients' and general practitioners' views. British journal of Psychiotry. 171. 169-174.

Cole, E., Leavey, G., King, M., of of (1995) Pathways to care for patients with a first episode of psychosis. A comparison of ethnic groups. British journal of Psychiatry 167. 770-776.

Koffiman, J., Fulop, N. J., Pashley, D. et ol (1997) Ethnicity and use of acute psychiatric beds: one-day survey in North and South Thames regions. British journal of Psychiatry, 17I, 238-241.

Parkman, S., Davies, S., Leese, M., et al (1997) Ethnic differences in satisfaction with mental health services among representative people with psychosis in South London: PRISM Study 4. British Journal of Psychiatry, I7I. 260-264.

G. Hutchinson, C. Gilvarry Department of Psychological Medicine, Institute of Psychiatry, De Crespigny Park, London SE5 8AF
Subjective memory complaints, depression and dementia

Sir: The report by Schmand et al (1997) confirms our own findings on a community sample of elderly subjects with subjective memory complaint (SMC) (Tobiansky et al, 1995).

Using the short-CARE nine-item screening instrument (Gurland et al, 1984 ), $87 \%$ of all elderly residents in one inner-London electoral ward were screened for the presence of objective memory disorder, depression and SMC in 1988, and again in 1990. In this way, we studied the value of SMC as a predictor of future depression or dementia in elderly residents. SMC was common, occurring in $25 \%$ of all subjects. Forty-seven per cent of subjects who fulfilled criteria for dementia and a similar percentage of those with depression had SMC.

When followed-up over two years, a sample of subjects with SMC who were neither demented nor depressed when first seen, were at a five-fold greater risk of developing future dementia and a 2.5-fold greater risk of developing depression compared with those without the complaint. The presence of SMC cannot be regarded as an entirely benign symptom.

In our study, uni- and multivariate comparisons indicated that certain SMC items ("Forgets what he/she had read or heard", "Forgets where he/she has placed things" and "Says impaired memory is a problem for him/her") were more likely to predict the onset of future dementia, while the item "Is embarrassed by memory problem" was more likely to predict depression.

A number of instruments have been developed for the purposes of quantifying self-ratings of memory failure (Dawe et al, 1992). Comparison of the short-CARE SMC scale with other SMC instruments would be of interest.

Dawe, B., Procter, A. \& Philpot, M. (1992) Concepts of mild memory impairment in the elderly and their relationship to dementia: a review. International journal of Geriatric Psychiatry, 7, 473-479.

Gurland, B. J., Golden, R. R., Toreal, J. A., ete ol (1984) The short-CARE: an efficient instrument for the assessment of depression, dementia and disability. Journal of Gerontology 39, 166-169.

Schmand, B., Jonker, C., Geerlings, M. I., et of (1997) Subjective memory complaints in the elderly: depressive symptoms and future dementia. British journal of Psychiatry I7I. 373-376.

Tobiansky, R., Blizand, R., Livingston, G., et af (1995) The Gospel Oak Study stage IV: the clinical relevance of subjective memory impairment in older people. Psychological Medicine, 25, 779-786.

R. Tobiansky Department of Old Age Psychiatry, Silkstream Unit, Colindale Hospital, London NW9 5 HG

\section{Lithium withdrawal mania supports lithium's antimanic action and suggests an animal model involving serotonin}

Sir: In his cogent response to Moncrieff's (1997) dismissal of lithium's therapeutic properties, Cookson (1997) points out that the well-documented occurrence of lithium withdrawal mania provides indirect evidence for the antimanic properties of lithium on which Moncrieff casts doubt.

Animal studies have also demonstrated behavioural changes associated with lithium withdrawal after long-term treatment, in which rats show increased attention and attraction to stimulus change without significant alterations in overall levels of motor activity (Harrison-Read, 1988). Similar behaviour occurs briefly during the initiation of lithium treatment, and may provide the basis for an animal model of the cognitive and emotional features of hypomania and mania.

During the course of long-term (three weeks or more) treatment with lithium in doses giving typical average plasma concentrations of $0.6 \mathrm{mmol} / \mathrm{l}$, rats develop behaviour (e.g. fore-paw treading) typical of a mild 'serotonin syndrome'. This abnormal behaviour can be attenuated by acute treatment with (-)-propranolol, possibly by blocking $5-\mathrm{HT}_{1}$ receptors within the brain. At the same time, propranolol unmasks the novelty-seeking behaviour characteristic of lithium withdrawal, even though lithium administration continues. Lithium-dependent novelty-seeking behaviour can, in turn, be selectively attenuated by drugs with $5-\mathrm{HT}_{2}$ receptor blocking properties, such as cyproheptadine.

In rats, at least, lithium initially appears to enhance cognitive and motivational processes by increasing neurotransmission at $5-\mathrm{HT}_{2}$ receptors, which somewhat paradoxically may mimic the situation in untreated patients with mania. These effects are later opposed and balanced by an increase in neurotransmission at $5-\mathrm{HT}_{1 \mathrm{~A}}$ receptors within the brain, possibly accounting for some of the antimanic and 
mood-stabilising properties of lithium in patients.

Enhanced 5-HT ${ }_{1 \mathrm{~A}}$ neurotransmission appears to dissipate within a few days of lithium withdrawal, revealing and leaving unopposed the pro-manic behavioural effects of increased 5- $\mathrm{HT}_{2}$ activity. These findings in animals support a hypothesis of $5-\mathrm{HT}_{2}$ receptor over-activity in mania and hypomania, with clear therapeutic indications. Indirectly, these findings also suggest that claims for lithium's therapeutic effects should not 'be taken with a pinch of salt'.

Cookson, J. (1997) Lithium: balancing risks and benefits. British Journal of Psychiotry, I17, 120-124.

Harrison-Read, P. E. (1988) Lithium differentially alters selective attention to novelty in rats depending on length of treatment and state of withdrawal: a possible role for 5-HT receptor subtypes. In Lithium: Orgonic Pharmocology and Psychiatric Use (ed. N. J. Burch), pp. 319-323. Oxford: IRL Press.

Moncrieff, J. (1997) Lithium: evidence reconsidered. British Journal of Psychiatry, 171, 113-119

P. E. Harrison-Read Park Royal Centre for Mental Health, Central Middlesex Hospital, Acton Lane, London NWIO 7NS

\section{Ethnicity and clozapine metabolism}

Sir: Taylor's review (1997) focused on the variability of clozapine metabolism from the effect of compounds on the cytochrome P450 system. We would like to highlight the possible influence of ethnicity on clozapine metabolism. To date, there are only three studies published in English of plasma clozapine levels in Asians. Chang et al (1993) found the daily mean plasma clozapine level of 77 of their Chinese patients with schizophrenia was significantly higher than those reported in American and European studies. Similarly, Chong et al (1997) found the mean plasma clozapine concentration attained in Chinese patients was higher than that reported in American studies, even though the Chinese patients had a lower mean daily dose of clozapine. However, it is difficult to interpret the findings from these two studies as comparisons were made with studies done elsewhere, by different workers and where many confounding variables were not controlled for. In a comparison study of 17 Korean-Americans and 17 Caucasians within the same treatment centre, Matsuda et al (1996) found a lower mean clozapine concentration in their Korean patients, which remained significant even after controlling for differences in daily clozapine doses. However, their study was limited by the small sample size and the failure to control for body weight. At present, there is only a suggestion of cross-ethnic differences in clozapine metabolism between Asians and Caucasians and perhaps even among Asian subgroups. More comparative studies need to be done before this can be resolved. These studies would need to control for variables like body weight, dose per kilogram, gender, and those compounds listed by Taylor (1997). Such studies should also guard against lumping the different Asian groups (Matsuda et al, 1996). We wish to emphasise that ethnicity is a confounding variable in psychopharmacology research and an important consideration in clinical practice.

Chang, W. H., Chein, C. P., Lin, S. K., et al (1993) Elevated clozapine concentrations in Chinese patients. Neuropsychopharmocology 9, 1175-1185.

Chong, S. A., Tan, C. H., Khoo, Y. H., et al (1997) Clinical evaluation and plasma clozapine concentrations in Chinese patients with schizophrenia. Therapeutic Drug Monitoring, 19, 219-223.

Matsuda, K. T., Cho, M. C., Lin, K. M., ot of (1996) Clozapine dosage, serum levels, efficacy, and side-effect profiles: A comparison of Korean-American and Caucasian patients. Psychophormocology Bulletin, 32. 253-257.

Taylor, D. (1997) Pharmacokinetic interactions involving clozapine. British journal of Psychiatry, 171, 109-112.

S.-A. Chong Woodbridge Hospital and Institute of Mental Health, 10 Buangkok Green, Singapore 539747

G. Remington Medication Assessment Program, Schizophrenia Division, Clarke Institute of Psychiatry, 250 College Street, Toronto, Ontario M5T IR8

\section{One hundred years ago}

\section{County Armagh Asylum}

At a meeting of the governors held on Jan. 10 th the new superintendent, Mr. Lawless, in his report said that the time had now come when it became necessary to consider the appointment of an assistant medical officer. He drew attention also to the fact that there was no supply of drinking water to the new hospital, the existing supply coming from the river-in his opinion a dangerous source. He suggested that they should apply to the town commissioners for a supply. The board decided that the matter of the appointment of an assistant medical officer should be postponed for the present.

Lancet. 15 January 1898,187

Researched by Henry Rollin, Emeritus Consultant Psychiatrist, Horton Hospital, Epsom, Surrey

\section{Erratum}

Fenton, W. S., Blyler, C. R., Wyatt, R. J., et al, BJP, 171, 265-268. In Table 1 (p. 266) the prevalence of dyskinesia among 94 patients in the Fenton et al (1994) study should read $23 \%$ (not $28 \%$ ). The authors apologise for any inconvenience caused by this error. 